\title{
Genetic Variation and Heritability Estimates for Indirect Measures of Freezing Tolerance during Fall Acclimation in Asparagus
}

\author{
Jaejoon Kim and David J. Wolyn ${ }^{1}$ \\ Department of Plant Agriculture, University of Guelph, Bovey Building, Guelph, Ontario, Canada \\ $N 1 G 2 W 1$
}

\begin{abstract}
Additional INDEX words. Asparagus officinalis, chlorophyll, fructan, glucose, percent water, proline, senescence, sucrose
Abstract. Winterhardiness is an important trait for asparagus (Asparagus officinalis) cultivars grown in temperate climates. Several biochemical and physiological parameters are correlated with the acquisition of freezing tolerance during cold acclimation in the fall and could be used as indirect measures for selection in a breeding program. Genetic variation was assessed before and after fall acclimation in August and November, respectively, for freezing tolerance attributes in 18 asparagus hybrids and 24 clones, which included male, supermale, and female genotypes. Fern chlorophyll and rhizome sucrose concentrations and storage root and rhizome percentage water decreased, whereas the concentrations of storage root proline, glucose and sucrose, and rhizome proline and high-molecular-weight fructan increased during the fall. Germplasm did not differ in August but significant variation was observed in November for most parameters, indicating genotype-specific responses to fall acclimation and the acquisition of traits associated with freezing tolerance. Narrow-sense heritability estimates were significant for fern chlorophyll, storage root proline, and rhizome glucose and sucrose concentrations. With significant genetic variation and heritability, breeding to improve freezing tolerance could be possible with indirect selection measures.
\end{abstract}

Asparagus (Asparagus officinalis) is an herbaceous perennial plant in which the above-ground fern senesces and dies in the fall, leaving only the below-ground crown to overwinter. In southern Ontario, where air and soil temperatures of -20 and $-5{ }^{\circ} \mathrm{C}$, respectively, are common for extended periods, freezing tolerance is essential for survival, and growers require cultivars adapted to the region for optimum productivity. Consequently, winterhardiness is an important objective in an asparagus breeding program.

Compounds with cryoprotective properties such as proline, glucose, sucrose, and fructans may contribute to freezing tolerance of the overwintering asparagus crown. Proline is known to stabilize protein synthesis, increase water-binding capacity of the cell, stabilize proteins during water stress, and promote expression of cold-responsive genes (Kandpal and Rao, 1985; Nikolopoulos and Manetas, 1991; Steponkus, 1984; Venekamp et al., 1989). Glucose and sucrose protect plant cells from freeze-induced dehydration and reduce ice formation by increasing the intracellular solute concentration as well as preventing structural changes to proteins (Caffrey et al., 1988; Vagujfalvi et al., 1999; Wilson et al., 2008). Fructans can have direct cryoprotective effects (Herman et al., 2006) through interaction with membranes to prevent dehydrative stress (Hincha et al., 2007) and their hydrolysis results in simple sugars (Gasecka et al., 2008) that may also act as cryoprotectant agents to increase freezing tolerance (Allison et al., 1999; Hincha et al., 2007).

Asparagus cultivars Guelph Millennium (GM) and Jersey Giant (JG) show different patterns of fall senescence and longevity in southern Ontario (Landry and Wolyn, 2011).

Received for publication 30 June 2014. Accepted for publication 2 Sept. 2014. Funding was provided by the Asparagus Farmers of Ontario, the Agricultural Adaptation Council and the Ontario Ministry of Agriculture and Food.

${ }^{1}$ Corresponding author. E-mail: dwolyn@uoguelph.ca.
GM senesces with fern turning yellow by mid-October and has sustained high yields over several years. JG has delayed senescence, is often green at the first killing frost, and suffers yield decline after several harvest seasons. Timely fall senescence was hypothesized to contribute to freezing tolerance and consequently improved longevity and yield. GM showed earlier accumulation of nitrogen and proline in the rhizome and earlier decrease in crown water percentage and fern chlorophyll concentration, indicators of dormancy and potentially increased freezing tolerance, compared with JG. The late initiation of senescence or active growth in the late fall was also negatively correlated with yield in asparagus (Bai and Kelly, 1999). In other plants such as alfalfa [Medicago sativa (Dhont et al., 2006)] and mayapple [Podophyllum peltatum (Watson and Lu, 1999)], early senescing lines showed greater freezing tolerance and long-term yield than those demonstrating late senescence. Asparagus cultivars with late senescence may be unadapted in southern Ontario as a result of the lack of metabolites flowing from the fern to the crown that could be important for both winterhardiness and spring vigor.

In seedling assays simulating fall acclimation under controlled conditions, GM had greater freezing tolerance than JG based on $\mathrm{LT}_{50}$ values (temperature at which $50 \%$ of plants die) (Landry and Wolyn, 2012; J. Kim and D.J. Wolyn unpublished data). In experiments with hybrids showing varying adaptation to southern Ontario, $\mathrm{LT}_{50}$ was highly correlated with seedling crown reducing sugar (Landry and Wolyn, 2012), proline, sucrose, and fructan concentrations and percentage water, and fern chlorophyll concentration (J. Kim and D.J. Wolyn, unpublished data).

The association of specific parameters with $\mathrm{LT}_{50}$ suggests that indirect measures of freezing tolerance could be used in a breeding program, especially to predict the trait in large populations acclimated in the fall under natural conditions. Effective breeding requires both genetic variation and heritability for 
attributes of interest. Therefore, the objectives of this study were to assess variation for biochemical and physiological parameters associated with freezing tolerance in asparagus germplasm and determine the heritability of these measures such that they may be useful for selection under field conditions.

\section{Materials and Methods}

Plant establishment. Asparagus plants were established at the University of Guelph research station in Simcoe, Ontario, Canada (lat. $42^{\circ} 51^{\prime} \mathrm{N}$, long. $80^{\circ} 16^{\prime} \mathrm{W}$, elevation $240.5 \mathrm{~m}$ ), in two replicate experiments in 2010 and 2011. Soil types were Oakland and Scotland Sand and Tavistock Loam in the 2 years, respectively.

On 15 Mar. 2010 and 21 Mar. 2011, seeds of 18 hybrids, derived by crossing six females and six supermales (Table 1), were planted in 288-cell plug trays filled with a peat-based soilless mix (Sunshine LC1; Sun Gro Horticulture Canada, Seba Beach, Alberta, Canada). In mid-April, seedlings were transplanted into 50-cell plug trays filled with another soilless mix (Sunshine LC5; Sun Gro Horticulture Canada) and grown in a greenhouse under natural light at $25 \pm 5^{\circ} \mathrm{C}$ until planted in the field. Twenty-eight female, male, or supermale clones (Table 1) of diverse pedigrees from the University of Guelph breeding program were propagated in vitro and transplanted into 50-cell plug trays in soilless mix (Sunshine LC5) in early May. Female and male clones are heterozygous and supermales may have resulted from one generation of selfing. Hybrids and clones were planted in the field on 17 and 18 June 2010 and 16 and 17 June 2011, where clonal entries were placed in six-plant plots and the seed-propagated entries were planted in nine-plant plots. The rows were spaced $1.25 \mathrm{~m}$ and plants spaced $30 \mathrm{~cm}$ within rows. Guard plants were planted at both ends of each row.

The experiment was conducted as a randomized complete block design with four blocks for each of the two replicate experiments planted in 2 separate years. Plots were sampled 15 Aug. and 7 Nov. 2011 and 13 Aug. and 5 Nov. 2012 for the experiments planted in 2010 and 2011, respectively. For statistical analyses, similar sampling dates over the 2 years were considered the same treatment level: mid-August (13 and 15 Aug.) and early November (5 and 7 Nov.). Three and four plants of clonal genotypes and hybrids, respectively, were sampled from each plot for each harvest date; the front half of the plot was sampled for the first harvest and the back half was sampled at the second harvest.

Field plots were fertilized $\left(10 \mathrm{~N}-4.4 \mathrm{P}-8.3 \mathrm{~K}\right.$ at $\left.50 \mathrm{~kg} \cdot \mathrm{ha}^{-1}\right)$ in May, June, and July of each year. Manual hoeing and interrow application of glyphosate (Roundup; Monsanto, St. Louis, MO) at a concentration of $360 \mathrm{~g} \cdot \mathrm{L}^{-1}$ were used to remove weeds as needed. Sprays for insects and diseases were applied as required (Ontario Ministry of Agriculture and Food, 2004).

SAMPLE HARVESTS. On each sampling day, cladophylls were selected randomly from top, mid-, and bottom parts of mature fern for each of the sampled plants; material was bulked separately for each plant and placed in a resealable plastic bag. Samples were placed on ice until frozen with liquid nitrogen and then stored at $-80{ }^{\circ} \mathrm{C}$ until further analysis. Crowns were manually dug from the field, cleaned of soil, and stored in bins covered with plastic bags, at $5{ }^{\circ} \mathrm{C}$, until sampling. The portion of the crown, where new buds were visible, was selected. Crowns were separated into storage roots
Table 1. Origin of asparagus clonal genotypes and hybrids based on breeding location for the cultivars from which original selections were made.

\begin{tabular}{|c|c|}
\hline Genotype $^{z}$ & Origin \\
\hline F01 & Ontario \\
\hline F02 & Western U.S., eastern U.S., Germany \\
\hline F03 & Western U.S., eastern U.S., Germany \\
\hline F04 & Ontario, eastern U.S. \\
\hline F05 & Unknown \\
\hline F06 & Germany-mixed ${ }^{\mathrm{x}}$ \\
\hline F07 & Germany, eastern U.S. \\
\hline F08 & Ontario, eastern U.S. \\
\hline F09 & Germany, eastern U.S. \\
\hline F10 & Germany-mixed \\
\hline F11 & Ontario \\
\hline $\mathrm{F} 12$ & Unknown \\
\hline F13 & Western U.S., eastern U.S., Germany \\
\hline M01 & Eastern U.S. \\
\hline SM01 & Western U.S., eastern U.S., Germany \\
\hline SM02 & Germany-mixed \\
\hline SM03 & Germany-mixed \\
\hline SM04 & Germany \\
\hline SM05 & Germany-mixed \\
\hline SM06 & The Netherlands \\
\hline SM07 & Taiwan \\
\hline SM08 & Unknown \\
\hline SM09 & Ontario, eastern U.S. \\
\hline SM10 & Germany \\
\hline Hyb01 & $\mathrm{F} 1 \times \mathrm{SM} 01$ \\
\hline Hyb02 & $\mathrm{F} 1 \times \mathrm{SM} 02$ \\
\hline Hyb03 & $\mathrm{F} 1 \times \mathrm{SM} 03$ \\
\hline Hyb04 & $\mathrm{F} 1 \times \mathrm{SM} 04$ \\
\hline Hyb05 & F1 $\times$ SM05 \\
\hline Hyb06 & $\mathrm{F} 2 \times \mathrm{SM} 01$ \\
\hline Hyb07 & $\mathrm{F} 2 \times \mathrm{SM} 02$ \\
\hline Hyb08 & $\mathrm{F} 2 \times \mathrm{SM} 03$ \\
\hline Hyb09 & $\mathrm{F} 2 \times \mathrm{SM} 04$ \\
\hline Hyb10 & $\mathrm{F} 2 \times \mathrm{SM} 11$ \\
\hline Hyb11 & F3 $\times$ SM0 1 \\
\hline Hyb12 & $\mathrm{F} 3 \times \mathrm{SM} 02$ \\
\hline Hyb13 & $\mathrm{F} 3 \times \mathrm{SM} 03$ \\
\hline Hyb14 & F3 $\times$ SM0 4 \\
\hline Hyb15 & F3 $\times$ SM05 \\
\hline Hyb16 & $\mathrm{F} 4 \times \mathrm{SM} 01$ \\
\hline Hyb17 & F5 × SM06 \\
\hline Hyb18 & Jersey Giant \\
\hline
\end{tabular}

${ }^{\mathrm{z}} \mathrm{F}=$ female; $\mathrm{SM}=$ supermale $\mathrm{M}=$ male; $\mathrm{Hyb}=$ hybrid.

${ }^{\mathrm{y}}$ Genotype derived by crossing selections from cultivars bred in multiple locations.

${ }^{\mathrm{x}}$ Mixed $=$ genotype derived by crossing selections from different cultivars developed in the same country.

and rhizomes. Storage roots were harvested near the rhizome in segments of $\approx 5 \mathrm{~cm}$, weighed, and placed in a resealable plastic bag. The rhizome from each crown was excised of bud scales and epidermal tissue and then placed in a plastic bag. Approximately 40 to $50 \mathrm{~g}$ fresh weight (FW) for each of the storage roots and rhizomes was bulked for each plot, weighed, frozen with liquid nitrogen, and stored at $-80{ }^{\circ} \mathrm{C}$. Samples were lyophilized (FreeZone 4.5L Freeze Dry System, Model 77510; LABCONCO, Kansas City, MO), then weighed, to determine 
dry weight (DW). Percent water was determined as $[(\mathrm{FW}-$ DW)/FW)] $\times 100$ (Tanino et al., 1990). Lyophilized samples were then ground with a Waring blender into a fine power that could pass through a 60 -mesh sieve and stored at $-80^{\circ} \mathrm{C}$ (Model 923; Forma Scientific, Marietta, $\mathrm{OH}$ ) until further use.

Metabolite analysis. Concentrations of chlorophyll in the fern and proline and high- and low-molecular-weight fructans in storage roots and rhizomes were determined as previously described (Landry and Wolyn, 2011). Glucose and sucrose concentrations were estimated with a Megazyme raffinose/ sucrose/glucose kit (product K-RAFGL; Megazyme International Ireland, Bray, Ireland) (McCleary et al., 2006); methods of Landry and Wolyn (2011) were followed with one modification. The rhizome and storage root samples were incubated with $5 \mathrm{~mL}$ of $95 \%(\mathrm{v} / \mathrm{v})$ ethanol to inactivate endogenous enzymes at the start of the assay.

Statistical analysis. The experiment was conducted using a randomized complete block design with four blocks in each replicate experiment. Data were normality distributed as determined by the Shapiro-Wilk test and univariate procedures. The statistical model included the fixed effects of genotype, harvest dates, and genotype $\times$ harvest date and the random effects of year, block, block (year), and their interactions with fixed effects. Data were analyzed with restricted maximum likelihood covariance estimates using the PROC MIXED procedure (SAS Version 9.3; SAS Institute, Cary, NC). Significance was detected at $P \leq 0.05$. To separate means, the Tukey's honestly significant difference test was conducted. Pearson correlation coefficients were generated using the PROC CORR procedure (SAS Version 9.3). Box plots were created using Excel 2007 (Microsoft, Redmond, WA).

Heritability estimation. For narrow-sense heritability estimates $\left(\mathrm{h}^{2}\right)$ of biochemical and physiological parameters, mean were estimated for 15 hybrids and their parents for each replicate experiment. All hybrids (Table 1) except 10, 17, and 18 were analyzed. Values for hybrids estimated in 2011 for Expt. 1 were regressed on midparent values estimated for Expt. 2 in 2012, and vice versa, to prevent bias resulting from environmental covariance (Fernandez and Miller, 1985; Vogel et al., 1980). The slope, determined by PROC REG in SAS, was the direct estimate of $\mathrm{h}^{2}$ (Falconer, 1981). Heritability was considered low for non-significant estimates and moderate for significant values ranging from 0.35 to 0.65 .

\section{Results}

Statistical analysis. The random effects of year and its interaction with the fixed effects of genotype, constituting clones and hybrids, harvest date, and genotype $\times$ harvest date interaction were not significant for all parameters tested; therefore, data were combined across 2 years. Significance of fixed effects for all variables is summarized (Table 2).

Genotypes did not vary for all parameters in August, when plants were growing actively. For the November sampling date, after cold acclimation, genotypes differed for storage root and rhizome percent water and fern chlorophyll, storage root proline, glucose and sucrose, and rhizome glucose, sucrose, and high-molecular-weight fructan (HF) concentrations.

Crown water Percentage. Median percent water was $80 \%$ for storage roots and rhizomes in August (Fig. 1A-B). Storage root percent water decreased in all germplasm at varying levels from August to November (data not shown); in November, clones and hybrids varied and values ranged from $63 \%$ to $72 \%$ (Fig. 1A).

For rhizome percent water, values decreased from August to November for only some clones and hybrids and the significant genotypic effect for the latter sampling date resulted from only one female clone having lower percent water than the other germplasm (data not shown). Median rhizome percent water decreased to $71 \%$ in November (Fig. 1B). Overall, percent water decreased from August to November in both the storage roots and rhizomes; variability among germplasm increased from August to November for storage root, but not rhizome percent water. Parent-offspring regression indicated low heritability for the trait in either organ (Table 3).

Chlorophyll. Fern chlorophyll concentrations decreased $45 \%$ to $74 \%$ among the clones and hybrids from August to November (data not shown); the average decline was $61 \%$ (Fig. 1C). In November, chlorophyll concentration varied among germplasm from $0.60(\mathrm{GM})$ to $1.30 \mathrm{mg} \cdot \mathrm{g}^{-1} \mathrm{FW}$. JG chlorophyll concentration was $1.05 \mathrm{mg} \cdot \mathrm{g}^{-1} \mathrm{FW}$ (data not shown). Overall, fern chlorophyll concentration decreased

Table 2. Significance of fixed effects for biochemical and physiological parameters related to freezing tolerance in asparagus. ${ }^{z}$

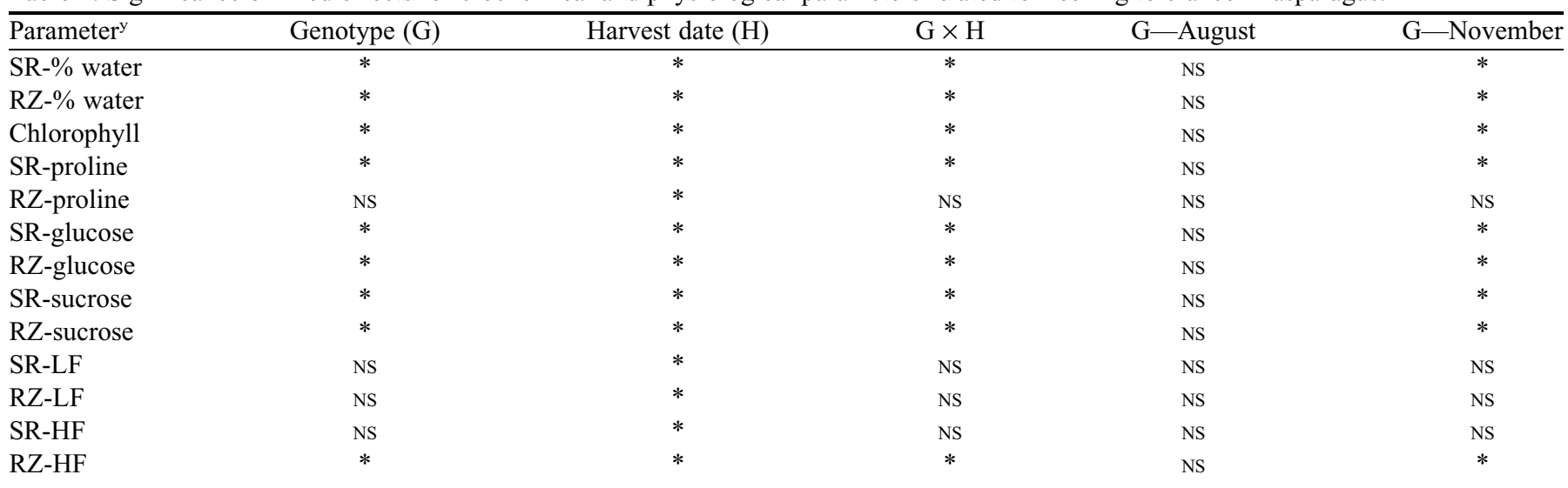

${ }^{\mathrm{z} F o r t y-t w o ~ c l o n e s ~ o r ~ h y b r i d s ~(g e n o t y p e s) ~ w e r e ~ h a r v e s t e d ~ i n ~ A u g u s t ~ a n d ~ N o v e m b e r, ~ a n d ~ d a t a ~ w e r e ~ p o o l e d ~ o v e r ~ t w o ~ e x p e r i m e n t s ~ f r o m ~ d i f f e r e n t ~}$ years.

${ }^{\mathrm{y}} \mathrm{SR}=$ storage root; $\mathrm{RZ}=$ rhizome; $\mathrm{LF}=$ low-molecular-weight fructan; HF $=$ high-molecular-weight fructan.

*Significant, $P \leq 0.05$; NS $=$ nonsignificant. 

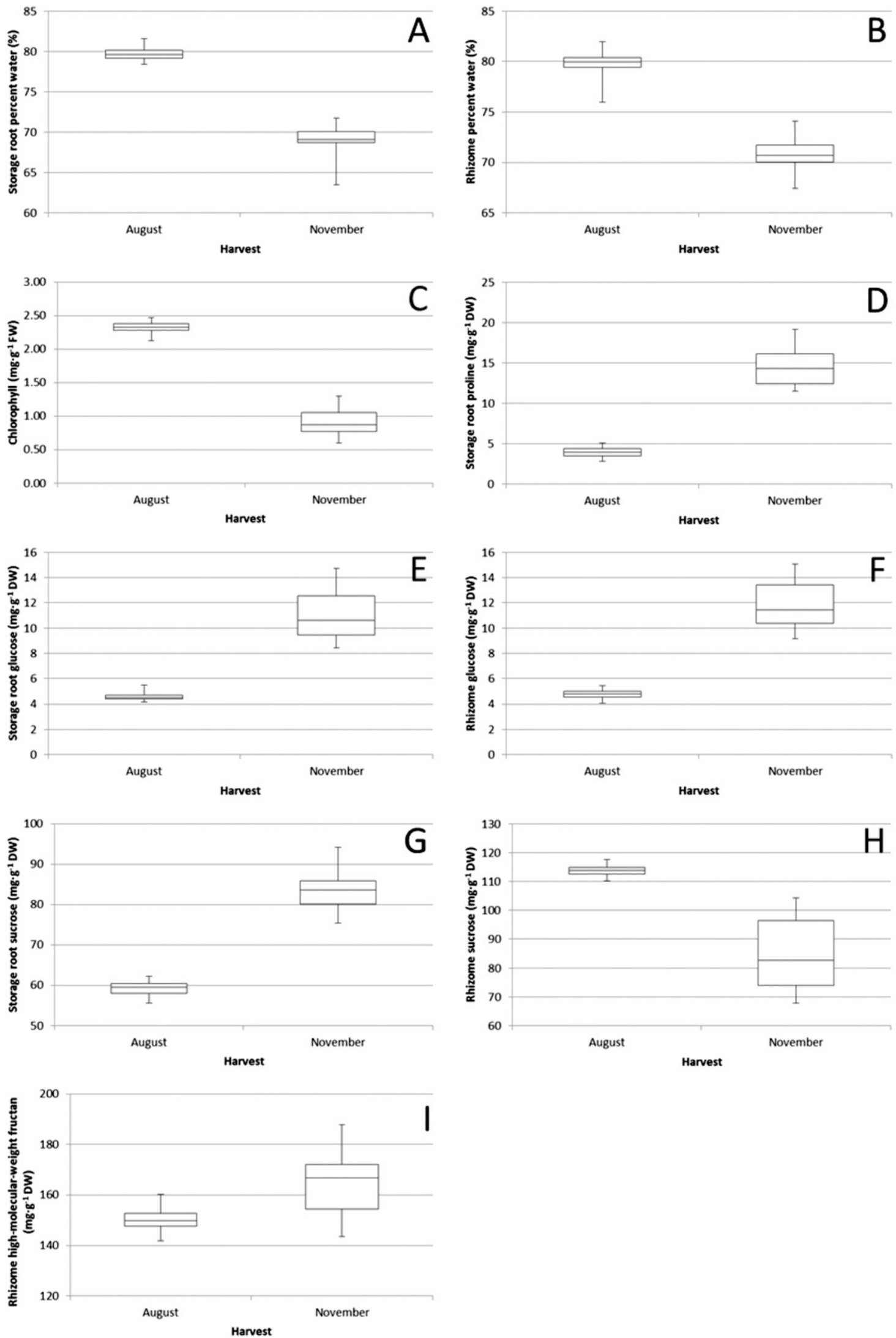

Fig. 1. Analysis of genetic variation for freezing tolerance traits (A-I) in asparagus sampled in August and November, presented as box plots. Data for 18 hybrids and 24 clones were combined over four blocks across 2 years $(2011$ and 2012) $(n=8)$. Vertical lines represent first (lower) and fourth (upper) quartiles and end (small horizontal line) at minimum and maximum values, respectively; boxes represent the second (lower) and third (upper) quartiles and intersect at the median; $\mathrm{DW}=$ dry weight; $\mathrm{FW}=$ fresh weight. 
Table 3. Narrow-sense heritability estimates $\left(h^{2}\right)$ derived from parentoffspring regressions of 15 hybrid and midparent values for biochemical and physiological parameters associated with freezing tolerance in asparagus. ${ }^{.}$

\begin{tabular}{lccccc}
\hline & \multicolumn{2}{c}{ Year 1 } & & \multicolumn{2}{c}{ Year 2 } \\
\cline { 2 - 3 } \cline { 5 - 6 } Parameter $^{\mathrm{y}}$ & $\mathrm{h}^{2}$ & $P$ value & & $\mathrm{h}^{2}$ & $P$ value \\
\hline Chlorophyll & 0.59 & $<0.001$ & & 0.52 & $<0.001$ \\
SR-\%water & 0.19 & 0.33 & & 0.38 & 0.31 \\
RZ-\%water & 0.32 & 0.08 & 0.39 & 0.67 \\
SR-proline & 0.53 & $<0.001$ & 0.46 & $<0.001$ \\
RZ-proline & 0.08 & 0.43 & 0.07 & 0.34 \\
SR-glucose & 0.10 & 0.38 & 0.10 & 0.42 \\
RZ-glucose & 0.49 & $<0.001$ & 0.53 & $<0.001$ \\
SR-sucrose & 0.00 & 0.98 & 0.07 & 0.76 \\
RZ-sucrose & 0.39 & $<0.001$ & 0.40 & $<0.001$ \\
SR-LF & 0.23 & 0.16 & 0.15 & 0.09 \\
RZ-LF & 0.02 & 0.81 & 0.11 & 0.49 \\
SR-HF & 0.01 & 0.94 & 0.08 & 0.49 \\
RZ-HF & 0.41 & 0.09 & 0.68 & $<0.01$ \\
\hline
\end{tabular}

${ }^{\mathrm{Z}}$ Independent experiments were replicated over 2 years and means of hybrids from the Year 1 experiment were regressed on the midparent estimates from the Year 2 experiment (Year 1) and vice versa (Year 2). ${ }^{\mathrm{y}} \mathrm{SR}=$ storage root; $\mathrm{RZ}=$ rhizome; $\mathrm{LF}=$ low-molecular-weight fructan; $\mathrm{HF}=$ high-molecular-weight fructan.

and variability among germplasm increased from August to November. Narrow-sense heritability estimates from parentoffspring regressions were moderate (Table 3 ).

Proline. Although germplasm did not vary for rhizome proline concentration at either harvest date, the effect of sampling time was significant (Table 2). Median proline concentration increased over 4-fold from August (4.82 mg. $\mathrm{g}^{-1}$ DW) to November (21.40 $\mathrm{mg} \cdot \mathrm{g}^{-1} \mathrm{DW}$ ) (data not shown).

Median storage root proline concentration was $4.01 \mathrm{mg} \cdot \mathrm{g}^{-1}$ DW in August (Fig. 1D) and values increased for individual clones and hybrids with fall acclimation (data not shown). Germplasm varied for storage root proline concentration in November with values ranging 11.5 to $19.1 \mathrm{mg} \cdot \mathrm{g}^{-1} \mathrm{DW}$. In general, proline concentration increased from August to November in both the storage roots and rhizomes; variability among germplasm increased from August to November for storage root, but not rhizome proline concentration. Moderate and low narrow-sense heritabilities were estimated for storage root and rhizome proline concentrations, respectively (Table 3).

GLucose. Median glucose concentrations in August were 4.61 and $4.76 \mathrm{mg} \cdot \mathrm{g}^{-1} \mathrm{DW}$ for storage roots and rhizomes (Fig. $1 \mathrm{E}-\mathrm{F})$, respectively. Storage root glucose concentration increased up to 3-fold from August to November, when values varied from 8.45 to $14.71 \mathrm{mg} \cdot \mathrm{g}^{-1} \mathrm{DW}$ (Fig. 1E). Rhizome glucose concentration increased similarly during the period and values in November ranged from 9.11 to $15.02 \mathrm{mg} \cdot \mathrm{g}^{-1} \mathrm{DW}$ (Fig. 1F). Germplasm showed dissimilar accumulation of glucose from August to November; concentrations increased more in storage root than rhizome for some clones or hybrids and vice versa (data not shown). Overall, glucose concentration increased from August to November in both the storage roots and rhizome; variability among germplasm increased from August to November for both tissues. Narrow-sense heritability estimates were moderate and low for rhizome and storage root glucose concentrations, respectively (Table 3 ).

Sucrose. Median storage root and rhizome sucrose concentrations in August were 59.2 and $113.8 \mathrm{mg} \cdot \mathrm{g}^{-1} \mathrm{DW}$, respectively
(Fig. 1G-H). Values for clones and hybrids increased for storage roots and decreased for rhizomes from August to November (data not shown). In November, storage root and rhizome sucrose concentrations ranged from 75.4 to 94.2 and 67.8 to $104.3 \mathrm{mg} \cdot \mathrm{g}^{-1}$ DW, respectively (Fig. 1G-H). Overall, sucrose concentration increased in storage roots and decreased in rhizomes from August to November; variability among germplasm increased from August to November for both tissues. Narrow-sense heritability estimates were moderate and low for rhizome and storage root sucrose concentrations, respectively (Table 3 ).

FruCTAN. Analysis of variance for storage root and rhizome low-molecular-weight fructan (LF) concentrations indicated only the effect of harvest date was significant (Table 2). Therefore, data were pooled over clones and hybrids for each harvest. Median storage root LF concentration decreased from 306 to $286 \mathrm{mg} \cdot \mathrm{g}^{-1} \mathrm{DW}$ across germplasm from August to November, respectively (data not shown). Rhizome LF increased significantly from August to November; median values across germplasm were 244 and $280 \mathrm{mg} \cdot \mathrm{g}^{-1} \mathrm{DW}$ for August and November, respectively (data not shown).

Rhizome HF concentration increased for individual clones and hybrids from August to November (data not shown); median values across germplasm increased from 150 to 167 $\mathrm{mg} \cdot \mathrm{g}^{-1} \mathrm{DW}$, respectively (Fig. 1I). Storage root HF concentration did not differ among germplasm for either harvest date; median values were $326 \mathrm{mg} \cdot \mathrm{g}^{-1} \mathrm{DW}$ in August and $390 \mathrm{mg} \cdot \mathrm{g}^{-1}$ DW in November. Overall, HF concentration increased from August to November in both the storage roots and rhizome, and differences among germplasm were only detected for rhizome HF in November. Total fructan accounted for up to $67 \%$ and $45 \%$ of the total dry mass in storage roots and rhizomes in November, respectively (data not shown). Narrow-sense heritability estimates for storage root and rhizome LF concentrations were low, whereas those for HF were moderate and low for rhizome and storage roots, respectively (Table 3).

Correlations. A limited number of parameters was correlated at the November harvest date (Table 4). Percent water was not associated with any parameter. Fern chlorophyll concentration was correlated with rhizome percent water and concentrations of storage root proline and glucose and rhizome glucose and sucrose. Storage root proline concentration was correlated with rhizome glucose, sucrose, and HF concentrations. Glucose concentration was associated with rhizome sucrose and HF concentrations. Rhizome sucrose and rhizome HF concentrations were also correlated.

\section{Discussion}

Asparagus phenology progresses from active summer growth to the acquisition of dormancy and freezing tolerance with fall senescence. In this study, clones and hybrids did not vary for freezing tolerance attributes in August, before the induction of senescence. Differences for many parameters were detected in November, indicating genetic variation for the cold acclimation response in the fall and traits could be improved by breeding. Variability was observed in November among germplasm for concentrations of fern chlorophyll, rhizome and storage root sucrose and glucose, storage root proline and rhizome HF as well as storage root and rhizome water percentage (Table 2). In general, fern chlorophyll and rhizome sucrose concentrations and storage root and rhizome percentage water decreased, whereas the concentrations of storage root 


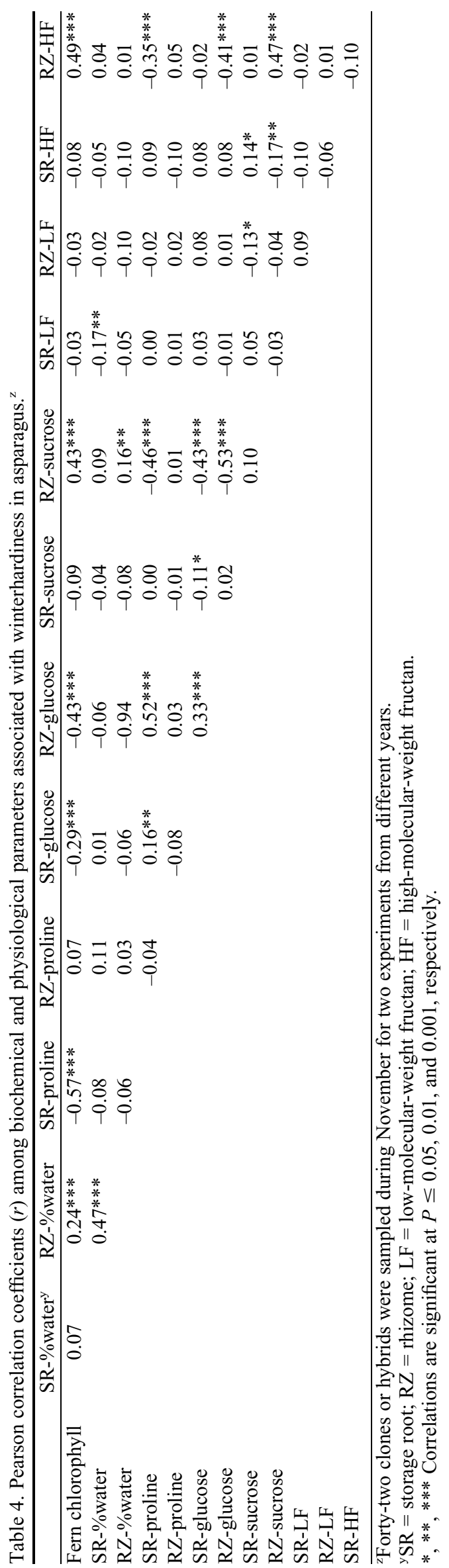

proline, glucose and sucrose, and rhizome proline and HF increased with fall acclimation. Narrow-sense heritabilities were significant for fern chlorophyll, storage root proline, and rhizome glucose and sucrose concentrations.

In this experiment, a select group of female, male, and supermale clones in the University of Guelph breeding program and hybrids were analyzed. The clonal lines represented individual genotypes selected from open-pollinated and/or hybrid cultivars bred in the western United States, eastern United States, Ontario, Germany, The Netherlands, and Taiwan and progeny of intermated selections. Clones with extreme susceptibility to winter-kill under local conditions would have been naturally eliminated from consideration. Despite the restricted group of evaluated germplasm, significant differences were observed among clones and hybrids after acclimation in November for traits previously associated with freezing tolerance, although the magnitude varied with each parameter (Fig. 1) and germplasm did not differ for all measures. These results are consistent with observations for GM and JG in a previous experiment (Landry and Wolyn, 2011) except for storage root percent water and both rhizome and storage root glucose, which did not differ between the two genotypes in the prior study but did differ among the germplasm studied here.

In seedling acclimation studies of cultivars with varying adaptation to southern Ontario that had high, intermediate, and low freezing tolerance under controlled conditions (J. Kim and D.J. Wolyn, unpublished data), low $\mathrm{LT}_{50}$, or high freezing tolerance was strongly associated with low crown percent water and fern chlorophyll concentration and high concentrations of crown proline, sucrose, LF, and HF ( $r \geq 0.75)$; the metabolites were also highly correlated. In the field experiment reported here, which did not consider highly unadapted germplasm, many parameters showed no correlation and most significant correlations ranged from 0.40 to 0.57 . These moderate associations could result from decreased germplasm variation in combination with experimental error from field plots compared with the seedling experiment with very diverse cultivars grown in growth chambers.

In the seedling acclimation studies, crowns were also too small to be separated into storage root and rhizome, whereas analyses in this experiment were conducted on the different organs; this discrepancy could have also affected the consistency of correlations. The differential sucrose accumulation in storage root and rhizome with fall acclimation in the field, reported here, is noteworthy. Sucrose concentration increased in storage roots and decreased in rhizomes from August to November (Fig. 1G-H). In the rhizome, and especially buds, sucrose is an indicator of active growth (Pressman et al., 1989) and low sucrose suggests dormancy. Therefore, the distinct difference between rhizome and storage root is important to consider if this parameter is used as an indirect measure of selection for freezing tolerance. The positive correlation between crown sucrose and freezing tolerance in seedlings could have been the result of storage roots accounting for most of the crown dry weight or the limited period of acclimation was insufficient to reduce sucrose in rhizomes.

Because fern chlorophyll, storage root proline, and rhizome glucose, sucrose, and HF concentrations had significant heritability, breeding for these parameters could result in increased freezing tolerance in this germplasm. Selection for timely senescence or decreased chlorophyll concentration in the field may be the simplest criterion to accelerate advancements in 
winterhardiness, especially in conjunction with vigor and longevity over multiple seasons.

Winterhardiness in asparagus is a complex trait likely affected by more than freezing tolerance during the coldest part of the year. Although selection based on the levels of indirect freezing tolerance measures in November or early winter can be beneficial to a breeding program, one may also consider the timing of acclimation and acquisition of traits. In the fall, some metabolic changes associated with freezing tolerance were observed weeks earlier for GM than JG (Landry and Wolyn, 2011). In years with early frost and freeze events, the timing of acclimation may be an important selection criterion, and monitoring metabolites in both mid-October and early November in southern Ontario could be beneficial. Timing of spring deacclimation can also be a critical component of winterhardiness for selection, because genotypes that release dormancy early could be susceptible to spring freezethaw cycles common in southern Ontario.

Despite the complexities of winterhardiness, this study demonstrated genetic variation and heritability for traits associated with freezing tolerance in late fall for germplasm generally adapted to cold temperatures of Ontario. Selection for low fern chlorophyll and rhizome sucrose and high storage root proline concentrations could be useful for improving this genetic material. Further analysis at different stages of acclimation and deacclimation can help optimize indirect selection for winterhardiness in asparagus.

\section{Literature Cited}

Allison, S., B. Chang, T. Randolph, and J. Carpenter. 1999. Hydrogen bonding between sugar and protein is responsible for inhibition of dehydration-induced protein unfolding. Arch. Biochem. Biophys. 365:289-298.

Bai, Y. and J. Kelly. 1999. A study of the photosynthetic activities of eight asparagus genotypes under field conditions. J. Amer. Soc. Hort. Sci. 124:61-66.

Caffrey, M., V. Fonseca, and A. Leopold. 1988. Lipid-sugar interactions-Relevance to anhydrous biology. Plant Physiol. 86:754 758.

Dhont, C., Y. Castonguay, P. Nadeau, G. Belanger, R. Drapeau, S. Laberge, J. Avice, and F. Chalifour. 2006. Nitrogen reserves, spring regrowth and winter survival of field-grown alfalfa (Medicago sativa) defoliated in the autumn. Ann. Bot. (Lond.) 97:109-120.

Falconer, D.S. 1981. Introduction to quantitative genetics. 2nd Ed. Longman, London, UK.

Fernandez, G. and J. Miller. 1985. Estimation of heritability by parentoffspring regression. Theor. Appl. Genet. 70:650-654.

Gasecka, M., J. Stachowiak, W. Krzesinski, M. Knaflewski, and P. Golinski. 2008. Changes in glucose, fructose and sucrose contents in storage roots of asparagus during vegetation period. Veg. Crops Res. Bul. 69:145-154.

Herman, E., K. Rotter, R. Premakumar, G. Elwinger, R. Bae, L. Ehler-King, S. Chen, and D. Livingston, III. 2006. Additional freeze hardiness in wheat acquired by exposure to $-3{ }^{\circ} \mathrm{C}$ is associated with extensive physiological morphological, and molecular changes. J. Expt. Bot. 57:3601-3618.

Hincha, D., D. Livingston, R. Premakumar, E. Zuther, N. Obel, C. Cacela, and A. Heyer. 2007. Fructans from oat and rye: Composition and effects on membrane stability during drying. Biochem. Biophys. ActaBiomembranes 1768:1611-1619.

Kandpal, R. and N. Rao. 1985. Alterations in the biosynthesis of proteins and nucleic-acids in finger millet (Eleucine coracana) seedlings during water-stress and the effect of proline on protein biosynthesis. Plant Sci. 40:73-79.

Landry, E. and D. Wolyn. 2011. Cold acclimation attributes of two asparagus cultivars with varying patterns of fern senescence. J. Amer. Soc. Hort. Sci. 136:177-189.

Landry, E. and D. Wolyn. 2012. A method to assess cold acclimation and freezing tolerance in asparagus seedlings. Can. J. Plant Sci. 92:271-277.

McCleary, B., S. Charnock, P. Rossiter, M. O'Shea, A. Power, and R. Lloyd. 2006. Measurement of carbohydrates in grain, feed and food. J. Sci. Food Agr. 86:1648-1661.

Nikolopoulos, D. and Y. Manetas. 1991. Compatible solutes and in vitro stability of salsola-soda enzymes-Proline incompatibility. Phytochemistry 30:411-413.

Ontario Ministry of Agriculture and Food. 2004. Field crop protection guide. Ontario Ministry Agr. Food Publ. 812.

Pressman, E., A. Schaffer, D. Compton, and E. Zamski. 1989. The effect of low temperature and drought on the carbohydrate content of asparagus. J. Plant Physiol. 134:209-213.

Steponkus, P. 1984. Role of the plasma-membrane in freezing injury and cold acclimation. Annu. Rev. Plant Physiol. 35:543-584.

Tanino, K., C. Weiser, L. Fuchigami, and T. Chen. 1990. Water content during abscisic acid induced freezing tolerance in bromegrass cells. Plant Physiol. 93:460-464.

Vagujfalvi, A., I. Kerepesi, G. Galiba, T. Tischner, and J. Sutka. 1999. Frost hardiness depending on carbohydrate changes during cold acclimation in wheat. Plant Sci. 144:85-92.

Venekamp, J., J. Lampe, and J. Koot. 1989. Organic acids as sources for drought-induced proline synthesis in field bean plants, Vicia faba L. J. Plant Physiol. 133:645-659.

Vogel, K., F. Haskins, and H. Gorz. 1980. Parent-progeny regression in indiangrass: Inflation of heritability environmental covariances. Crop Sci. 20:580-582.

Watson, M. and Y. Lu. 1999. Timing of shoot senescence and demographic expression in the clonal perennial Podophyllum peltatum (Berberidaceae). Oikos 86:67-78.

Wilson, D., S. Sinton, R. Butler, D. Drost, P. Paschold, G. Kruistum, J. Poll, C. Garcin, R. Pertierra, I. Vidal, and K. Green. 2008. Carbohydrates and yield physiology of asparagus: A global overview. Acta Hort. 776:413-427. 